\section{A CASE OF UPWARD DISLOCATION OF THE FOO'T.}

BY PERCY W. G. SARGENT, M.A., M.B., B.C. CANTAB, F.R.C.S. KNG.,

RESIDENT' ASSTSTANT SURGEON TO ST. 'THOMAS'S HOSPITAL, LONDON.

I AM indebted to the late Professor William Anderson for permission to make use of the following case which was admitted to St. Thomas's Hospital under his care in 1899. It appears from the literature of the subject to be an accident of extreme rarity, the salient features of the case being that the astragalus, retaining its normal relations with the foot, was driven upwards between the tibia and fibula without fracture of either bone.

Th ; patient was a short muscular man, aged 46 years, a carman bj occupation. He fell from a loft, a distance of about nine feet, and alighted on the soles of the feet upon a heap of stones, falling to the ground immediately and twi,ting his foot in so doing. There was no history of any previous injury or disease of the joint. On examination, as the patient lay on his back upon the couch with the legs extended, the right foot rested on its outer border, having been rotated at the ankle through a complete right angle. The relations of the tarsal and metatarsal bones to one another were unaltered. The tibia lay in its natural position, the crest and internal malleolus being markedly prominent, whilst the fibula was displaced backwards. The inferior articular surface of the tibia could be distinctly felt beneath the tightly stretched skin which was in no place lacerated. The heel was markedly prominent. The illustration from a plaster cast taken shortly after the accident (see figure) shows the widening between the malleoli, which amounted

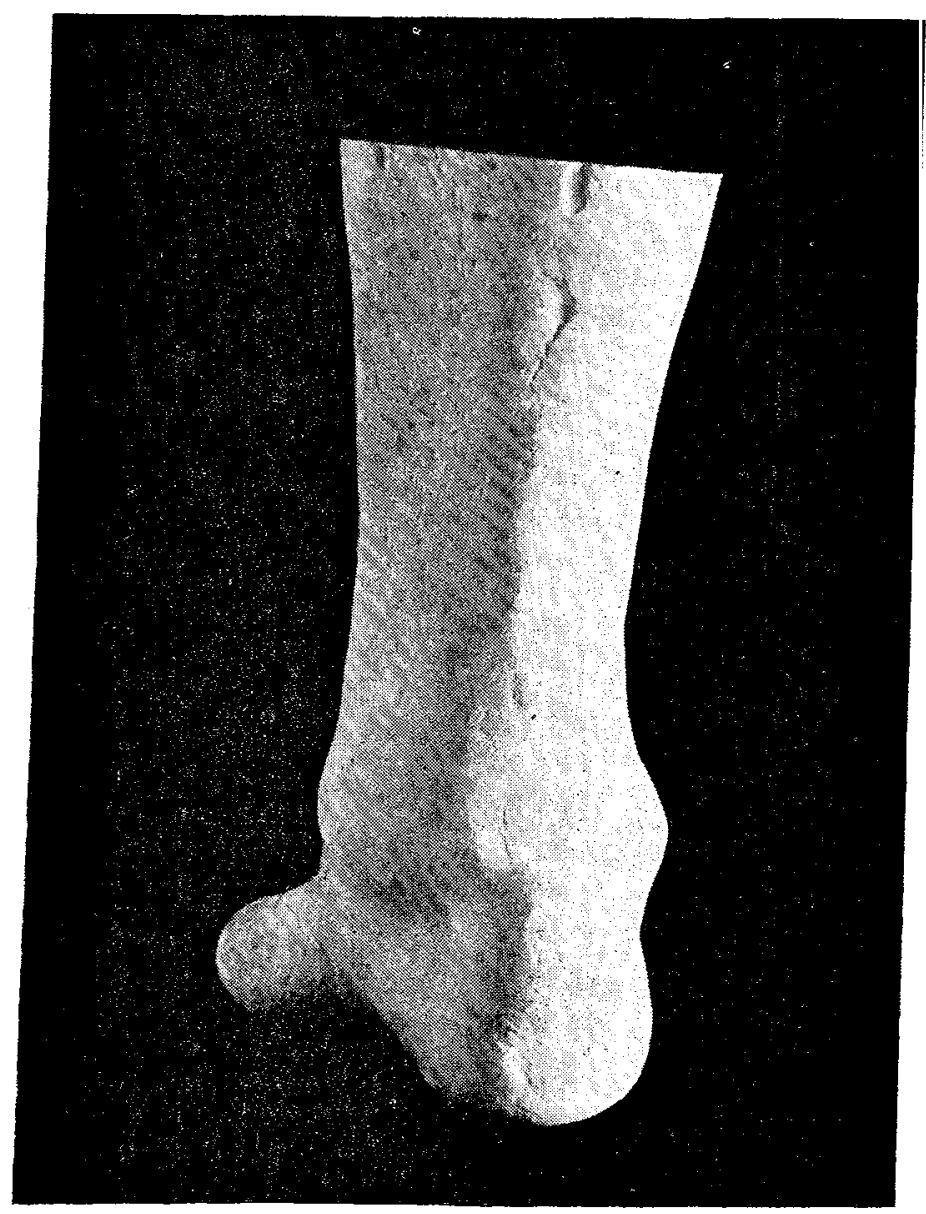

From a photograph of a plaster cast of the foot taken shortly after the accident.

to over two inches, and the approximation of the malleoli to the plane of the sole. No evidence of fracture could be obtained either by manipulation or by means of the $x$ rays as seen in a skiagram which was taken by the late Dr. Barry Blacker. The foot was firmly fixed in its new position. Under an anæsthetic the dislocation was readily reduced by simple traction on the foot. Massage and passive movements were begun on the third day and the patient was able to walk with only a slight limp at the end of three weeks. He subsequently made a complete recovery.

The dislocation appears the more remarkable when the enormous strength of the ligaments uniting the lower extremities of the tibia and fibula is considered. As described by Mr. Henry Morris ${ }^{1}$ these are : (1) inferior interosseous, a dense felted mass of short fibres passing transversely one and a half inches in deptb, and extending between (2) the anterior and posterior inferior tibio-fibular ligaments ; and (3) the transverse inferior tibio-fibular ligament. Experimentally on the dead subject the dislocation could not be imitated until not only these and the lateral ligaments of the ankle but also the lower part of the interosseous membrane had been divided. In spite of their great strength these ligaments must have been ruptured, since there is no evidence that any portion of either bone was torn away. As the superior articular surface of the astragalus is wider in front than behind extreme dorsal flexion of the foot puts these ligaments upon the stretch and tends to separate the tibia and the fibula. If now the foot is so fixed as to prevent movement at the mid-tarsal joint and then forcibly everted as a whole, the tendency is still farther to separate the two bones and also to bring the outer edge of the upper articular surface of the astragalus agajnst the inferior tibio-fibular ligaments. In this position if force is applied upwards to the foot this edge of the astragalus will form the thin edge of a wedge and thus the whole bone can be forced upwards, separating the tibia from the fibula. In the present instance the foot was rotated outwards through a right angle and the fibula displaced backwards, so that a further movement of supination must have taken place at the superior tibio-fibular joint. There was no evidence of dislocation at that joint or of fracture of the fibula.

I have been able to find only one similar case recorded. This one, of which there is a cast in Guy's Hospital Museum, is described by Bryant ${ }^{2}$ Il occurred in both feet simultaneously, in a man, aged 38 years, who fell from a scaffold. The malleoli were widely separated and projected; the depth of the foot from the malleoli to the plane of the sole was lessened and there was no evidence of fracture. The feet were firmly fixed in the abnormal position and reduction being found impossible the patient recovered with stiff joints. Bryant ${ }^{3}$ also mentions a case of a similar nature but complicated with fracture of the astragalus. In Treves's "System of Surgery"4 Mr. A. Marmaduke Sheild describes the accident as being excessively rare and points out that fracture of the malleoli may complicate it. $\mathrm{Mr}$. G. H. Makins remarks that there is some doubt as to whether in such cases the separation of the tibia and fibula is not actually due to an oblique fracture of the tibia; and notes that reduction has proved extremely difficult or impossible. Hamilton ${ }^{6}$ speaks of a lateral dislocation of the tibia from the fibula at the lower end, where the fibula may remain unbroken and undisturbed, the tibia having become displaced inwards. He points out the rarity of absence of fracture and notes that the injury is usually compound. Boyer ${ }^{7}$ writes : "I have had the opportunity of seeing an incomplete dislocation of the astragalus upwards ('en haut') and inwards in a man who had fallen from a horse" but no mention is made of fracture. This also remained unreduced. Nélaton" says: "The upward dislocation necessitates at the same time a fracture of the fibula, and a separation of its inferior extremity from the tibia. The astragalus retains its normal direction but is raised between the two bones." He also points out the increase of the intermalleolar measurement, the proximity of the malleoli to the sole. and the immobility of the foot. Benjamin Anger" quotes Nélaton as to the name "luxation en haut" but gives neither description nor instance. $\mathrm{He}$ describes a case of " dislocation by rotation," the foot having been turned outwards through a right angle but without separation of the tibia and fibula.

Summary.-The chief points of interest in this case, some of which can be observed in the reproduction of a photograph

1 H. Morris : A Treatise on Anatomy, article "The Articulations." 2 Bryant: System of Surgery, vol. ii., p. 838.

\& Treves: System of Surgery, vol. ii., p. 1020.

5 International Text-book of Surgery, article "Dislncationd." Hamilton: Fractures and Dislocations, p. 773 7 Boyer : Traité des Maladies Chirurgicales, p. 406 8 Nélaton: Pathologie Chirurgicale, tome iii, p. 292 9 Benjamin Anger: Traité des Maladies Chirurgicales, artiale "Luxatione et Fractures." 
of the cast, seem to be : (1) the increase of the intermalleolar measurement; (2) the prominence of the heel ; $(3)$ the approximation of the malleoli to the plane of the sole ; (4) the absence of fracture; (5) that the injury was not compound; and (6) the extreme ease with which reduction was effected.

\section{NOTE ON A CASE OF RENAL CALCULUS.} BY H. E. BRUCE PORTER, M.R.C.S. ENG., L. R.C.P. LOND.

THIS note upon a case of suppuration of the right kidney caused by a calculus which first gave rise to symptoms 12 years ago and which for the whole time was mistaken for sciatica may be interesting in the light of recent correspondence in THE LANCET upon sciatica.

The patient, a woman, aged 35 years, sent for me early in 1901. When asked what she complained of she seemed to make light of her trouble, replying, "Oh, it is only a touch of my old friend sciatica." As the patient was to my mind rather young to have old friends of such a nature my next query was, "When did you first have sciatica?" I was informed 12 years ago and that it was so bad that she was in bed for some weeks, her then medical attendant devoting much thought to the case and using every means in his power to cut short the attack. As the treatment had no effect on the disease she was sent to the German baths and spent the best part of three years seeking relief without much success. My next query was, "Please tell me about your present attack." The patient replied that she had lunched out and drove home in a dogcart; she felt rather out of sorts and during the night had a shivering fit which returned off and on for some hours. The pain was of a dull character in the right side, there was frequent micturition, and her temperature was $102^{\circ} \mathrm{F}$. The right kidney seemed the most probable seat of trouble and it was felt to be enlarged and tender; there was no tenderness over the sciatic region. I now returned to the history of the sciatica of 12 years or so ago. The onset of this was sudden while out walking and, in the patient's words, she walked home doubled up with pain. This did not sound like sciatica. Freryone knows how a patient with this trouble walkseertainly not doubled up. The pain ran down the inside and outside of the thigh and at times was in the sole of the foot. It was not affected by the position of the leg-in fact, as she put it, the pain made her squirm. The first attack lasted, as I have said, off and on for three years and during this time she believed that the urine was examined she had never noticed blood in it. For the last nine years she had always had an uncomfortable feeling in her right side and occasionally attacks of " sciatica" (?). During these attacks she had noticed the urine to be thick but took no particnlar notice beyond observing the fact.

The patient was married about four years ago and was pregnant for the first time 12 months later. When three months pregnant the pain in the right side became worse; she also had so much swelling of the hands that she could not wear her rings; she was given to understand that this was due to her pregnancy and her urine was not examined. The pain in the right loin during the later months of pregnancy was worse but was all put down to the nterus. Since the birth of her child she had had to give up many of her pursuits and from being active became the reverse. At times she was unable to bear anything tight around the waist. The lungs were quite healthy and there were no signs of wasting -in fact, considering the history the patient was very well nourished. There was no history of phthisis. I ordered the whole of the urine passed during the next 24 hours to be saved in one vessel, the clear portion to be poured off, and the sediment to be sent to me. This contained one-sixth albumin; a few pus cells were to be recognised under the microscope but no blood or crystals except arates. I came to the conclusion that the case was either calculous kidney or tuberculons disease of the kidney, that the attack 12 years ago had been renal colic, and that during pregnancy the change had become more rapid in the breaking down of renal tissue. I advised complete rest and also advised the husband to have a second opinion, pointing out that the urine ought to be examined by a bacteriologist to exclude as far as possible the tuberculous cause.
Dr. Archibald $\mathbf{E}$. Garrod made an examination. In the urine of the second 24 hours there was more pus (about three drachms). He agreed with my view of the case and took a specimen of urine to town to have it examined for tubercle. It was found free from tubercle and though the negative result did not exclude the possibility of tuberculous disease it was an additional point as there was no evidence of trouble in the chest, and the history of what we were both agreed was an attack of renal colic 12 years previously made us hope the case would prove to be one of calculons kidney. The temperature varied between $102^{\circ} \mathrm{F}$. at night and $100.4^{\circ}$ in the morning. On Feb. 25th the patient's child being put on the bed pressed against the damaged kidney, the result being that the swelling was much greater. It could now be seen as an oblong tumour in the right side of the abdomen. On the morning of the $26 \mathrm{th}$, as the pus was not coming away freely enough, hot fomentations were applied. On the 27th the pus was coming away more freely. Sir Frederick Treves came to see the patient to decide when he would advise operation. He confirmed ty his examination of the case and history the view taken by Dr. Garrod and myself-i.e., that the trouble began with an attack of renal colic which was then taken for sciatica. He decided that it was a case for removing (when the active stage had passed and the temperature had become normal) what was a serious menace to life. Pus continued to come away and on May 6th the patient's temperature touched the normal line in the morning, rising to $99 \cdot 4^{\circ}$ at night. As it was necessary to have the patient in a surgical home in town for the operation $I$ allowed her up for one hour on the 8 th. The temperature went up to $99.6^{\circ}$ in the evening. On the 9 th the temperature was again normal. The patient was up for three hours. The tempera. ture on going to bed was $101^{\circ}$ but came down after she had been in bed about an hour. On the 11th I took the patient to town and she stood the journey well. On the 13th Sir Frederick Treves operated. The organ was removed from the front; an incision was made along the right semilunar line for a considerable extent. The other kidney was examined and found to be quite healthy; the ovaries were also felt and found to be healthy; the right kidney was adherent at the upper end so the lower was delivered first. It is not necessary to describe the various steps of the operation, so I will content myself with saying that the wound was closed without the insertion of a drainage-tube and the patient was taken back to bed. The kidney was a mere shell of pus ; there was not a trace of renal tissue left. It contained at least 15 onnces of pus. The calculus which had evidently started the trouble had become quite disintegrated. The patient had a good night and the urine passed was quite healthy. The patient made a good recovery except for the delay caused by the formation of an abscess in connexion with the stump of the ureter. About ten months later the patient became pregnant and this pregnancy was free from the pains, \&c., of the former one. The child was born at term. I think the case of interest as showing that in a young woman the symptoms caused by a renal calculus had given rise to the idea that she was suffering from sciatica. The patient is now in perfect health and certainly looks and feels years younger.

Windsor.

\section{THE TREATMENT OF SCIATICA.}

\section{BI J. Michell OLARKE, M.A., M.D. Cantab} F.R.C P. LOND.,

PROTESSOR OF PATHOLOGY, UNIVERSTTX COLLEGE, BRISTOL; PHYSICIAN TO THE BRISTOL GENERAT HOSPITAI.

MY reason for writing this short paper is that I believe that the Weir-Mitchell method of treatment of sciatica by immobilisation of the affected limb by means of the long splint is not so generally employed as it deserves to be. It is true that there are references to the method in some of the text-books but they are brief, and although Dr. I. Burney Yeo gives a longer and more satisfactory description in the last edition of his "Manual of Medical Treatment," it does not seem to be generally known that obstinate and protracted cases of scirtica can be successfully dealt with in this way. It is not my intention to enter into the oiscussion of what is the exact nature of sciatica but to confine myself to a brief statement of $\mathrm{my}$ experience of this particalar 